\title{
1 Research Assessment Using Early Citation Information
}

2 Stephan B. Bruns

3 Meta-Research in Economics Group and INCHER, University of Kassel, Nora-Platiel-Str. 5,

434109 Kassel, Germany. E-mail: bruns@uni-kassel.de, Phone: +49 5618042709.

5 David I. Stern

6 Crawford School of Public Policy, The Australian National University, 132 Lennox Crossing,

7 Acton, ACT 2601, Australia. E-mail: david.stern@anu.edu.au. Phone: +61-2-6125-0176.

84 May 2016

\section{Abstract}

10 Peer-review based research assessment, as implemented in Australia, the United Kingdom, 11 and some other countries, is a very costly exercise. We show that university rankings in 12 economics based on long-run citation counts can be easily predicted using early citations. 13 This would allow a research assessment to predict the relative long-run impact of articles 14 published by a university immediately at the end of the evaluation period. We compare these 15 citation-based university rankings with the rankings of the 2010 Excellence in Research 16 assessment in Australia and the 2008 Research Assessment Exercise in the United Kingdom. 17 Rank correlations are quite strong, but there are some differences between rankings. 18 However, if assessors are willing to consider citation analysis to assess some disciplines, as is 19 the case for the natural sciences and psychology in Australia, it seems reasonable to consider 20 also including economics in that set.

21 Keywords: Citations, research assessment, bibliometrics

22 JEL Codes: A14, H83, I23

\section{Acknowledgments}

24 We thank Guido Bünstorf and an anonymous referee for valuable comments and Andreas 25 Rehs and Immanuel Bachem for helpful research assistance. 
1

2

3

4

5

6

7

8

9

10

11

12

13

14

15

16

\section{Introduction}

In assessments of university research, as carried out in the social sciences in Australia and in all fields in Britain, publications that have already passed through a peer-review process at academic journals and presses are again peer reviewed by the assessment panels. This involves a significant workload for the many academics that are supposed to read these publications in addition to the effort each university must put into selecting the publications that will be reviewed. Farla and Simonds (2015) find that the total economic cost of the 2014 Research Excellence Framework (REF) in the United Kingdom (UK) was £246 million (\$384 million). Moreover, as Sayer (2014) argues, this second peer review is inferior to the first. If instead citation-based metrics were used, as is the case for the natural sciences and psychology in Australia, the assessment could be done much faster and cheaper. In this article, we provide evidence on the potential effectiveness of citation analysis as a method of research assessment in economics, a discipline subject to peer review in both the UK and Australia. We hope our results can inform the future development of assessment exercises such as the Excellence in Research in Australia (ERA) and REF. Though the Higher Education Founding Council in England (HEFCE) Metrics Review (Wilsdon et al., 2015) rejected metrics-only assessment, at the time of writing the British government was again assessing the possibility of reducing the costs of the REF (Department of Business, Innovation \& Skills and Johnson, 2015).

Stern (2014) shows that long-run citations to articles in economics and political science can be predicted quite well using the first few years of citations to those articles. This predictability in economics and political science is similar to that found in several natural sciences by other researchers (Adams, 2005; Waltman et al., 2011; Wang, 2013). However, research assessment, as practiced in Australia and the UK, evaluates universities rather than single articles. Here we show that rank correlations are greatly increased when we aggregate over the economics publications of a university and also when we aggregate publications over time. The rank correlation between UK universities ranked by citations received till the end of 2005 for economics articles published in 2003 and 2004 and UK universities ranked by total citations to those articles received through 2014 is 0.97 . Rank correlations between university rankings based on the same early citations and university rankings implied by the research assessment exercises in the UK and Australia range from 0.67-0.76. Though these rank correlations are quite high, deviations between the peer-review based rankings and our citation-based rankings may be partly explained by the differences between our simulated 
assessments and how an actual assessment would be conducted. Our results suggest that citation analysis could be useful for research assessment in economics if assessors are willing to use cumulative citations as a measure of research strength, though there do appear to be some systematic differences between peer-review based research assessment and our citation analysis, especially in the UK.

The belief that citations accumulate too slowly in most social sciences such as economics to be useful for short-term research assessment is a reason why citation analysis is less accepted in the social sciences than in the natural sciences (Bornmann and Leydesdorff, 2014). Our results show that citations definitely accumulate fast enough in economics at the department or university level in order to be able to predict the longer run citation outcomes of recent publications. However, while the Australian Government's ERA exercise uses citations to recent publications to assess research performance in natural science disciplines and psychology, peer review is used in other social science disciplines. The Australian Research Council (ARC) instructs peer reviewers not to take citation numbers or journal rankings into account when assessing the quality of submissions. The Research Assessment Exercise (RAE) and its successor the REF in the UK uses peer review as the main method of assessment for all disciplines. REF panels can also put some weight on citations data in some disciplines including most natural sciences and economics (Sgroi and Oswald, 2013), but only as a positive indicator of academic significance and in very much a secondary role to peer review (Holgate, 2015). This represents a change from the previous RAE, which prohibited the use of citations data by panels. ${ }^{1}$

Previous research (Adams, 2005; Levitt and Thelwall, 2011; Waltman et al., 2011; Wang et al., 2013; Stern, 2014) predicts the future cumulative citations of individual articles based on early cumulative citations and other variables such as journal impact factors. However, in research assessment exercises, such as the REF and ERA, whole universities are assessed in each discipline and a corpus of research outputs covering several years is reviewed. ${ }^{2}$ There

1 A variety of research assessment models are in place in different countries (Key Perspectives, 2009). Research assessment exercises in other countries use different combinations of peer review and bibliometric analysis. For example, the Italian Evaluation of Research Quality must peer review at least half the submitted research items (Bertocchi et al., 2015). In the U.S., the National Research Council carries out a periodical assessment of doctoral programs. The 2011 assessment (Ostriker et al., 2011) covered 5000 doctoral programs at 212 universities. The most recent assessment aggregated various quantitative metrics, including numbers of citations, using weights derived from a survey of faculty on the importance of the various metrics.

${ }^{2}$ In New Zealand though, individual researchers are assessed (Anderson and Tressler, 2014). 
are a number of reasons why aggregating publications by departments should increase the predictability of citations compared to predicting the citations of an individual article:

1. A portfolio effect - idiosyncratic or random variations in the time paths of citations received by individual articles are averaged away. Aggregation across time will also contribute to the portfolio effect. ${ }^{3}$

2. A size effect - variation in the size of departments introduces an additional correlation between the total numbers of early and cumulative citations.

3. A quality effect - the size of departments is positively correlated with their research quality (Mryglod et al., 2013), which will further increase the correlation between the total numbers of early and cumulative citations across departments.

If we want to allocate research funds according to research strength - combining both the quantity and quality of research - then these effects are advantageous.

The next section of the paper reviews recent research on research assessment and citation analysis. Following this, we present our methods, data sources, and results. Finally, we present some discussion and conclusions.

\section{Peer Review and Citation Analysis in Research Assessment}

Existing research finds strong correlations between the rankings produced by UK research assessment exercises and bibliometric analyses for several specific humanities and social science disciplines (e.g. Colman et al., 1995; Oppenheim, 1996; Norris and Oppenheim, 2003) including economics (Süssmuth et al., 2006; HEFCE, 2015). Clerides et al. (2011) compare the 1996 and 2001 RAE ratings of economics departments with independent rankings from the academic literature. They find RAE ratings to be largely in agreement with the profession's view of research quality as documented by independent rankings, although the latter appear to be more focused on research quality at the top end of academic achievement. This is because most rankings of departments in the economics literature are based on publications in top journals only, which lower-ranked departments have very few of.

Mryglod et al. (2013) analyze the correlations between the values of the Thomson Reuters Normalized Citation Impact (NCI) indicator and RAE 2008 peer-review scores in several

\footnotetext{
${ }^{3}$ Of course, this effect will also apply to many other ways of aggregating publications including random samples of publications.
} 
academic disciplines. The NCI computes the normalized (by field) impact factor across a unit of assessment (an academic discipline at a given university) in the RAE based on only the publications actually submitted to the RAE. Mryglod et al. (2013) compute both average and total, or quality and strength (Kenna and Berche, 2011), values of the RAE 2008 peer-review scores and NCI for each university. Research strength is the average value, or quality, of each of these two indicators for a unit of assessment multiplied by the number of staff submitted to the RAE. They find very high correlations for the strength indicators for some disciplines and poor correlations for the quality indicators for all disciplines. Moreover, the correlation between peer-evaluated and citation-based scores is weaker for the "soft" sciences. Spearman rank correlation coefficients for their quality indicators range from 0.18 (mechanical engineering) to 0.62 (chemistry). For strength, however, the correlations range from 0.88 (history and sociology) to 0.97 (biology). This is because quality is correlated with size and so the two factors reinforce each other.

Mryglod et al. (2015) attempt to predict the results of the 2008 RAE retrospectively and those of the 2014 REF before they were released. They examined biology, chemistry, physics, and sociology. Of the indicators they trialed, they found that the departmental h-index had the best fit to the 2008 results. Departmental h-index is based on all publications published by a department in the time window assessed by the relevant assessment exercise. The rank correlation ranged from 0.83 in chemistry to 0.58 in sociology. They find that the correlation with the RAE ranking for the immediate h-index is as good as the correlation with the hindex computed in later years for the same set of publications.

However, despite these findings, Bornmann and Leydesdorff (2014) argue that one of the downsides of bibliometrics, as a research assessment instrument, is that citations take time to accumulate while research assessment exercises are designed to assess recent performance:

"This disadvantage of bibliometrics is chiefly a problem with the evaluation of institutions where the research performance of recent years is generally assessed, about which bibliometrics - the measurement of impact based on citations - can say little.... the standard practice of using a citation window of only 3 years nevertheless seems to be too small." (1230)

They argue further that bibliometrics:

"can be applied well in the natural sciences, but its application to TSH (technical and social sciences and humanities) is limited." (1231) 
1 Rather than assuming that peer review is the preferred approach to research assessment and 2 citation analysis should only be used to reduce costs, we can ask whether the review conducted by research assessments such as the REF and ERA meets the normal academic standards for peer review. Research does show that peer review at journals has predictive validity for the citations that will be received by accepted papers compared to those received by rejected papers. However, evidence for the predictive validity of peer review of grant and fellowship applications is more mixed (Bornmann, 2011; Gallo et al., 2014), and Sayer (2014) argues that the peer review undertaken in research assessment exercises does not meet normal standards for peer review. He compares processes used in the REF at the university and national levels to practices of scholarly review found in academic journals, university presses, and North American tenure procedures. He finds that the peer-review process used by the REF falls far short of the level of scrutiny or accuracy of these more familiar peerreview processes. The number of items each reviewer has to assess, means that the review cannot be of the same quality as reviews for publication. And reviewers will have to assess much material outside their area of specific expertise. Sayer argues that though metrics may have problems, a process that gives such extraordinary gatekeeping power to individual panel members is far worse. Moreover, Wooding et al. (2015) find "grade inflation" between RAE 2008 and REF 2014. The number of world-leading (denoted by $4 *$ in RAE) publications increased by $103 \%$ between 2008 and 2014. But the increase in UK research articles among the $10 \%$ most cited globally was only $10-25 \%$. Therefore, there seems to be a lack of consistency in evaluation over time.

Given the large number of items that panels need to review they are likely to focus on the venue of publication and, at least in business and economics, handy mappings of journals to REF grades exist (Hudson, 2013). HEFCE (2015) finds that economics and econometrics is the field with the strongest correlation at the individual publication level between scores in REF 2014 and the impact factors of journals in which the articles were published. This suggests that REF reviewers mostly used journal reputation to assess articles. Regibeau and Rockett (2014) build imaginary economics departments entirely composed of Nobel Prize winners and evaluate them using standard journal rankings geared to the UK RAE. Performing the same evaluation on existing departments, they find that the rating of the Nobel Prize departments does not stand out from other good departments. But if departments composed entirely of Nobel Prize winners perform worse than current departments then it is hard to know what such assessment means. Also, compared to actual recent research evaluations, the Nobel Prize departments' rankings are less stable over time. They argue that 
1 this is because the rankings exercise leads departments to hire people with appropriate recent

2 publications to fill any gaps in their performance. They also find that including more than 3 each researcher's best four publications enhances the relative performance of the Nobel Prize 4 departments. $^{4}$

5 Sgroi and Oswald (2013) examine how research assessment panels could most effectively use 6 citation data to replace peer review. They suggest a Bayesian approach that uses prior 7 information on where an item was published combined with observations on citations to 8 derive a posterior distribution for the quality of a publication. We could then estimate, for example, what is the probability that a publication belongs in the $4^{*}$ category given where it was published and the early citations it has received. Stern (2014) and Levitt and Thelwall (2011) show that the journal impact factor has strong explanatory power in the year of publication but that this declines very quickly as citations accumulate. So, this approach would be most useful for papers published in the last year or two before the assessment, but for earlier research outputs in the assessment window the added value over simply counting citations would be minimal.

\section{Data and Methods}

\section{Data}

We used the Web of Science to download bibliographic information on all articles that were published by a university in Australia and the UK in 2003 and 2004 in the Web of Science

20 Category "Economics", which included 169 journals in 2003 and 172 journals in $2004 .{ }^{5}$ The number of journals covered rose steeply after 2006 reaching 333 in 2013 . This means that the potential to receive citations that are included in the database has increased substantially over our assessment window. Although this affects cumulative citations, we do not expect that it benefits some universities more than others. We restrict our analysis to the document types "Article", "Article; Proceedings Paper", and "Review". Reviews are articles with more than

\footnotetext{
${ }^{4}$ The REF, and previously the RAE, assesses only four publications for each submitted researcher. The submitting university chooses both which researchers and which of their publications to submit.

${ }^{5}$ The vast majority of bibliometric research uses the Web of Science as its data source. One reason for this is that it allows researchers to easily download the results of searches as data files. This data includes year-by-year citations to each article. Though Google Scholar covers a wider range of citing and cited sources, it is very noisy with many misidentified publications and citations. Constructing a data set for a discipline in a country would be a very labor-intensive process. Scopus is also not as user-friendly as the Web of Science. For example, one cannot search by discipline in Scopus.
} 
1100 references. We also separately downloaded all citations to these articles in each year

2 from 2003 to 2014. We downloaded the data in September 2014 and all citations until then 3 are included in our data. We combined the separate dataset containing information on the 4 authors and their affiliations with the citations dataset using the name of the article, the 5 name(s) of the author(s), the beginning page and the ending page of each article, which are 6 found in both datasets.

7 We then selected all articles where at least one author has an affiliation with an address that 8 contains "Australia" or at least one author has an affiliation with an address that contains 9 "England", "Scotland", "Northern Ireland" or "Wales". We also searched for United 10 Kingdom and UK, but no article used these terms in the authors' affiliations. As the names of 11 the universities are not harmonized in the Web of Science, many different ways of writing the 12 name of the same university are present in the data. We identified and harmonized the 13 university names by hand to allocate articles to universities and removed articles that did not include a university-based author.

15 Our data contains 293 articles in 2003 and 321 articles in 2004 that were published by authors with at least one affiliation to a university in Australia. For the UK, we have 1155 articles in 2003 and 1132 articles in 2004 that were published by authors with at least one affiliation to a university in the UK.

19 Each article is potentially written by multiple authors, and each author may be potentially affiliated with multiple universities. The Web of Science data contains the affiliations listed on the article, which depends on the style used by the journal and, therefore, does not unambiguously identify how many researchers from a given university were authors of a given article. Some journals list each university once irrespective of how many authors of an article are actually affiliated with that university, while others may list the same university multiple times if multiple authors are affiliated with the same university. We count each article only once for each university irrespective of how often the same university may be listed on the article due to these data limitations.

Counting each article once for each university is also reasonable given how actual research assessments are conducted. In the ERA, each publication is counted once for each university. However, a single publication can be submitted in more than one discipline area for a single university in which case it only has a fractional weight in each discipline. The RAE usually only allows authors at the same university to submit the same publication if they are 
1 submitting under different "units of assessment" or disciplines. Co-authors at different

2 universities can each submit the publication for full credit in the same unit of assessment.

3 Therefore, in most cases our count of articles will match the ERA or RAE.

\section{Methods}

5 We are interested, first of all, in how well a ranking of universities in economics that is based on early citations can predict a university ranking that is based on cumulative citations over a longer period. We also test this predictability for an alternative ranking based on the number of publications of each university among the top $10 \%$ of publications by citations. Second, we are interested in how strongly correlated our rankings are with the outcomes of actual research assessment exercises. We conduct our analysis separately for Australia and the UK.

To compute rank correlations between universities' early and cumulative citations we aggregate each university's citations for articles published in 2003 over the periods 2003, 2003-2004, 2003-2005, and 2003-2014. We then calculate the rank correlation (Spearman) between universities ranked by cumulative citations (2003-2014) and universities ranked by early citations (2003, 2003-2004, or 2003-2005). Spearman's rank correlation coefficient is a special case of the general correlation coefficient. In particular, it uses the average rank if multiple universities have the same number of citations. For example, if the top five universities have 100,100,100, 90, and 80 citations, the ranks used in the Spearman rank correlation are 2, 2, 2, 4, and 5. We carry out the same analysis for articles published in 2004, using the early citation windows 2004, 2004-5, and 2004-6, and for the set of articles from both 2003 and 2004, using 2003-4, 2003-5, and 2003-6 citation windows.

We also consider the subgroup of universities that actually submitted to the ERA 2010 and RAE 2008. Many UK universities that produced some economics research did not submit the discipline to the RAE (Johnston et al., 2014). Finally, we also compute the rank correlation between individual articles ranked by early citations and ranked by cumulative citations to demonstrate the effect of aggregating articles across a university.

27 In addition to total citations, we consider university rankings based on each university's number of articles in the top $10 \%$ of articles. The top $10 \%$ of articles are defined by early or cumulative citations for the respective country and publication window. For example, the top $10 \%$ of articles published in 2003 for the citation window 2003-2005 in the UK, are those $10 \%$ of UK articles published in 2003 that have the highest total citations between 2003-

32 2005. This indicator is the same as the Leiden size-dependent indicator P(top 10\%) (Waltman 
1 et al., 2012). This indicator reduces the effect of outlier articles with very high numbers of

2 citations and should reward consistent quality more.

3 Finally, we analyze the rank correlations between universities ranked by (early and 4 cumulative) citations and universities ranked by the measures of research quality produced by 5 the ERA 2010 (Australia) and research strength and quality produced by the RAE 2008 (UK).

6 RAE 2008 evaluates universities by determining the fractions of each university's 7 publications that fall into categories $4^{*}, 3^{*}, 2^{*}$, and $1^{*}$ that reflect research that is "world 8 leading", “internationally excellent", "recognized internationally", and "recognized 9 nationally", respectively. The quality measure of RAE 2008 is calculated as a weighted sum of the shares of research falling into categories $4^{*}, 3^{*}, 2^{*}$, and $1^{*}$ using the weights $4,3,2$, 11 and 1. This is the method used by UK newspapers to derive a ranking from the RAE and REF 12 results. We compute the strength measure for RAE 2008 by multiplying the quality measure 13 with the number of full time equivalent employees that were submitted to RAE 2008. We 14 also consider an alternative RAE 2008 ranking based on the funding allocated as a result of the exercise. Here we weight the shares of research falling in the $4^{*}, 3^{*}, 2^{*}$, and $1^{*}$ categories by $9,3,1$, and 0 respectively, which was the actual weighting used for distributing funding at that time. ERA 2010 provides a rating of universities that directly corresponds to a quality ranking. The information provided in ERA 2010 does not let us compute a strength ranking 19 for Australia.

\section{Results}

Table 1 presents the rank correlations between universities ranked by early citations and universities ranked by cumulative citations for Australia and the UK based on articles published in 2003, 2004, and aggregated over time (2003 and 2004). The table also presents the rank correlations between individual articles ranked by early citations and ranked by cumulative citations. Additionally, the table presents rank correlations based on the number of articles each university published in the top $10 \%$ of articles.

With regards to total citations at the article level, the rank correlations are higher for the UK than for Australia but both are lower than those presented by Stern (2014) for the global set of economics articles. Stern (2014) reports a rank correlation of 0.36 between 2006 citations and cumulative 2006-2012 citations for economics articles published in 2006 (0.73 if 2006-7 is compared with 2006-12). For articles published in 1999, the rank correlation between 1999 citations and 1999-2012 citations was 0.33 (0.60 if 1999-2000 is compared to 1999-2012). It 
seems to be easier to predict citations using a global data set than a data set for a single country. It is possible that this is because in a larger sample there are more highly cited articles with individual ranks and gaps in the numbers of citations between them that increase predictability. In Australia, both the mean and standard deviation of citations received by an article is smaller than the world average so that the Australian sample of articles is more alike in the number of citations received than the world sample is. For 2003 articles, the mean and standard deviation of cumulative citations are for Australia 15 and 22, for the UK 23 and 58, and for the world 21 and 50.

More importantly, aggregating citations over universities increases the rank correlations tremendously. The rank correlations are higher for the UK than for Australia, but three years of citations (2004-6) already generates a rank correlation of 0.95 for Australia using 2004 articles alone, so this difference is not so important.

Excluding universities that did not submit to RAE 2008 makes little difference to the results and excluding universities that did not submit to ERA 2010 makes no difference at all to the results. In the first case, those universities that did not submit had few publications, and in the latter case there are very few such universities that published in economics but did not submit.

Aggregating 2003 and 2004 articles together increases the rank correlations relative to using only 2003 citations to 2003 articles but actually slightly reduces the rank correlations compared to using a two-year window for the 2003 articles alone. In Australia the rank correlation between the university ranking based on citations received in 2003-4 for 2003 articles and the university ranking based on cumulative citations for 2003 articles is 0.88 but this decreases to 0.82 by adding the 2004 articles, which only have a rank correlation of 0.65 between their 2004 and cumulative citations. This shows that including very recent articles, which have had less than a year to accumulate citations, in the assessment can reduce the correlation with long-run citations. In actual research assessment exercises more than two years are evaluated and this issue is likely to play a minor role. Research assessment exercises might consider discounting the articles published in the last year of the assessment period or using additional information for these articles, e.g. journal impact factors, potentially in a Bayesian framework as suggested by Sgroi and Oswald (2013). In the UK, adding the 2004 articles to the 2003 ones only reduces the rank correlation from 0.92 to 0.91 and the rank correlation for the universities that submitted to RAE 2008 remains constant at 0.96. Therefore, adding this additional information might not be worthwhile. 
1 In most cases, the rank correlations between universities ranked by the number of articles in

2 the top $10 \%$ of articles based on early citations and universities ranked by the number of 3 articles in the top $10 \%$ based on cumulative citations are lower than for total citations, though 4 the gap narrows when we aggregate articles over two years. It is particularly noticeable that 5 in some cases widening the citation window increases predictability relatively little for this 6 indicator, though this behavior is quite erratic.

7 Table 2 presents rank correlations between university rankings based on total citations 8 accumulated over various windows and the rankings implied by ERA 2010 and RAE 2008. 9 These rank correlations are quite low for the UK and are a bit higher for Australia. The ERA 10 process must be more similar to a total citation counting exercise than the UK process despite 11 providing only a quality rather than a strength metric. The correlation between citations and 12 the RAE quality measure is lower than that with the strength measure, as we would expect, but this difference reduces when we aggregate over two years of articles.

14 For the UK, the length of the citation window makes almost no difference to the rank 15 correlation. This is not surprising, as the rank correlation between universities ranked by early citations and universities ranked by cumulative citations is already quite high with just a one-year early citation window. Hence, the citation-based rankings do not differ substantially with respect to the citations window. For Australia, the rank correlation between the ERA 2010 ranking and the ranking based on citations rises as the citation window is extended. This is consistent with the smaller rank correlations between universities ranked by early citations and universities ranked by cumulative citations for Australia. It seems that the ranking based on cumulative citations better matches the ranking based on ERA 2010.

The Table also presents rank correlations between the rankings implied by the research assessment exercises and the university's number of articles in the top 10\% of articles. These correlations are lower for the UK and tend to decrease as the citation window is lengthened. This indicates that the ranking of universities based on the number of articles in the top $10 \%$ better matches the RAE 2008 rankings when early rather than cumulative citations are used to calculate the university's number of articles in the top $10 \%$ of articles. This is much less noticeable for Australia. We do not know the reason for this, but can speculate that some articles that eventually accumulate a large number of citations are considered less important by both early citers and research assessment reviewers, who assess articles relatively soon 32 after they are published. 
1 Aggregating over two years of publications increases the rank correlations between the

2 rankings of the research assessments and both the university rankings based on citations and 3 the university rankings based on the number of articles in the top $10 \%$. This seems to be due

4 to year-to-year volatility in the citations rankings of low ranked universities. Table 3 shows

5 the rankings of UK universities based on RAE 2008 and total citations with various citations

6 windows. For example, University of Edinburgh goes from a rank of 3 in 2003 to 16 in 2004

7 and Queen Mary from 12 to 25. Edinburgh's high ranking for 2003 articles is due to a single

8 econometrics article (Im et al., 2003) that received a very high number of citations.

9 Table 4 shows the rankings of Australian universities based on ERA 2010 and total citations 10 with various citation windows. Both Table 3 and 4 show that rankings based on early 11 citations are very similar to those based on citations accumulated over a longer period at the 12 university level. The Tables allow us to see which particular universities reduce the rank correlation between the research assessment ranking and our citation-based ranking. We see that the University of Essex was highly ranked in RAE 2008 but low ranked by cumulative citations for articles from 2003-4. Another notable anomaly is St Andrews. The reverse is true of East Anglia, Sussex, Sheffield, and Edinburgh. This may be related to the fields of specialization of these universities. East Anglia specializes in environmental economics, which typically has relatively high citation counts, as well as development economics. Sheffield has a specialization in health economics, which is also likely to get high citation counts due to citing from outside of economics. Essex has strengths in labor economics and micro-theory.

Table 5 provides some information on the research outputs of these universities. The four universities that rank high by citations compared to their RAE ranking all published many more articles relative to the number of staff they submitted to the RAE than the two universities that ranked low by citations compared to their RAE ranking. This may be because of different models of publication in different fields - rates of publication per academic do seem anecdotally high in environmental and health economics compared to more traditional economics fields. It could also be because these universities only submitted a narrow subset of their staff engaged in economics research to the economics unit of assessment. Edinburgh scored a very high number of citations from the article by $\operatorname{Im}$ et al. (2003). The other three universities' most cited papers are in environmental or health economics. Whereas the journals most published in at St Andrews and Essex are traditional 
1 economics journals, the journals most published in at the other universities are more

2 specialized or interdisciplinary journals.

3 Of course, another important reason for divergence between our citation counts and the RAE

4 is likely to be, as we mentioned above, that not all researchers publishing in the economics

5 journals that we capture are affiliated with an economics department and were submitted to

6 the economics unit of assessment in the RAE. This is likely to be especially true for Sussex

7 and East Anglia, two universities where there are large non-economics academic units that

8 produce some publications in economics.

9 There are fewer obvious outliers in Australia, and due to the longer period between 2003-4 and the research assessment in 2010 there was more opportunity for universities to improve their performance in the interim. This certainly explains the high ranking awarded to UTS and anecdotally could explain some of the other apparent anomalies. For example, UTS recruited Michael Keene in 2006 (left for UNSW in 2011) on an ARC Federation Fellowship

14 and John Geweke - currently the $2^{\text {nd }}$ ranked economist in Australia according to RePEc - in 152009.

\section{Discussion}

17 Our results show that cumulative citations are highly predictable by early citations at the university discipline level in economics. However, the results of our citation-based rankings differ from those that are based on peer review, though to a lesser degree in Australia than in the UK. One reason for this, suggested in the previous section, is that we do not normalize by citation potential. Some fields, such as environmental and health economics might have higher citation potential due to greater interest outside of economics. On the other hand, small fields such as economic history have lower citation potential. Source normalized impact factors are now available for journals (Moed, 2012) and for universities as a whole (Waltmann and van Eck, 2013). An actual research assessment exercise could control for citation potential, perhaps by using regression analysis (Bornmann, in press).

27 Differences between our citation-based rankings and the peer-review rankings can be also explained by differences between the set of publications we analyzed and those used in the ERA 2010 and RAE 2008. First, we only use two years of data rather than 5 or 6. Second, universities have considerable leeway regarding the publications they submit in each discipline area. In Australia, the university can, for example, decide whether to submit an article under the economics field of research (FoR 14) or the policy and administration one 
1 (FoR 1605) or whether to submit another article under econometrics (FoR 1403) or statistics

2 (FoR 0104). ${ }^{6}$ In the UK, a researcher might, for example, be assigned to the economics unit 3 of assessment (UoA 34) or the accounting and finance unit of assessment (UoA 35). We

4 simply decide what is an economics article based on the journal it was published in and some

5 of the journals we included, such as Economic Geography and a number of finance journals,

6 would not usually be considered as core economics journals, though they are included in the

7 economics category in the Web of Science. Third, we only count publications that are in

8 journals included in the Web of Science. In Australia, all research publications published by a

9 university in the field of research are submitted to the ERA. This includes articles in any

10 peer-reviewed journal as well as books, book chapters, and conference papers. Universities

11 have discretion over submitting "grey literature" such as government reports. There is also

12 discretion over submitting the publications of affiliated faculty such as emeritus professors

13 and visiting fellows. In the UK, only the four best publications of each included researcher

14 are submitted and universities can decide not to submit researchers to the RAE. So, compared

15 to the ERA we are probably less comprehensive in coverage but probably more

16 comprehensive in coverage than the RAE. Finally, we assign articles to the universities to

which their authors were affiliated at the time of publication. Both the ERA and RAE assign

publications to the universities their authors were affiliated with at the time of assessment. ${ }^{7}$

We also computed and evaluated a number of quality indicators including the impact factor of each university's articles and the $\mathrm{PP}($ top 10\%) indicator, which is the proportion (rather than number) of a university's articles published in the top $10 \%$ most cited articles (Waltmann et al., 2012). The rankings produced by these indicators were not very intuitive, with some small universities that are not usually regarded as highly ranked appearing ahead of more highly regarded universities such as LSE. We think that there are two reasons for this. First, the number of articles published by some of these universities in Web of Science journals is very low and sampling variability means that an occasional highly cited article produced by these universities distorts these quality indicators. For example, de Montfort

\footnotetext{
${ }^{6}$ In ERA 2010 and 2012 publications assigned to four-digit fields of research (e.g. economic theory or econometrics) with less than fifty publications in total, were not assessed. In ERA 2015 these were assessed as part of the two-digit field of research (e.g. economics) even though the four-digit field will not be assessed. This seems to be a move to reduce gaming of the system by assigning weak publications to four-digit codes that were then not assessed.

${ }^{7}$ RAE 2008 included publications published from 2001 to 2007 inclusively by researchers affiliated with eligible institutions on 31 October 2007 and included by their university in its submission. The 2010 ERA included publications published from 2003 to 2008 inclusively by researchers affiliated with eligible institutions on 31 March 2009.
} 
1 University only has 2 articles in our sample, which received a total of 68 citations through

2 2014. Second, universities with lower actual research quality publish many articles in 3 journals that are not included in the Web of Science. This is especially true in the period we 4 are considering when there were only about 160 economics journals included in the Web of 5 Science. The articles included in the Web of Science are their better articles. Truncating their 6 output in this way results in an upward-biased estimate of their average quality compared to 7 universities with actually higher average research quality. This is the second main reason why 8 many researchers oppose using citation analysis to assess research quality in the social 9 sciences (Bornmann and Leydesdorff, 2014). But as articles in Web of Science journals are 10 cited much more on average than articles in other journals, these considerations will have much less effect on strength indicators.

12 Research assessments may change the structure of the economic discipline. Johnston et al. 13 (2014) show that the total number of economics students increased in UK more rapidly than 14 the total number of all students, but the number of departments offering economics degrees has declined, particularly in post-1992 universities. Also, the number of universities submitting to the REF under economics has declined sharply with only 3 post-1992 universities submitting in the latest round. This suggests that the REF has driven a concentration of economics research in the more elite universities in the UK - the question is whether that means that predicting ranks is easier in the UK than it is in other countries.

There has also been an increased emphasis on research in Australia. Neri and Rodgers (2015) investigate the output of top economics research by Australian academics from 2001 to 2010 .

22 They construct a database of 26,219 publications in 45 top journals finding that Australia's output, in absolute and relative terms, and controlling for differences in page size and journal quality, increased and, on a per capita basis, is converging to the levels of the most researchintensive countries. They also find that the historical dominance of the top four universities is diminishing. So the effects of a greater emphasis on research seem to be reversed in 27 Australia. This is probably because, unlike the UK, so far very little spending is determined on the basis of research assessment. Neri and Rodgers also find that the correlation between the number of top 45 journal articles published in 2005-2010 and the ERA 2012 ranking is 0.83 (0.78 for 2003-8 and ERA 2010). 


\section{Conclusions}

In this paper, we have shown that when we aggregate individual articles across the economics discipline at a university, the university ranking based on cumulative citations for articles published in 2003 and 2004 can be easily predicted by the university ranking based on citations received until the end of 2004. Enlarging the citation window increases predictability further. Predictability is slightly higher for the UK than for Australia and higher for total citations than for the number of articles a university published in the top $10 \%$ most cited articles. Therefore, if we are interested in research strength, and are prepared to measure that by cumulative citations received, we can certainly use early citations as a reliable predictor of the relative research strength of different universities in economics. The argument that citations accumulate too slowly in the social sciences to be of use is not true at the aggregate level of universities.

However, we found that measures of research quality we constructed using the Web of Science data did not produce intuitive results. This is likely because many publications of weaker universities in research terms are not included in the Web of Science and so average citation measures for these departments are biased upwards. Today, compared to our study period in 2003-4, the number of social science journals included in the Web of Science has increased and Scopus includes even more social science journals. Therefore, a research assessment conducted today may be better able to compute quality measures if they were desired.

We find that our citation-based rankings have moderate correlations with the rankings implied by ERA 2010 and RAE 2008. The correlations are higher for Australia despite only a quality type ranking being available for Australia. The previous section discussed some reasons why our model research assessment will capture a different set of publications than were actually assessed in these exercises. Additionally, we noted that the citation potential of different fields within economics might differ and that this should be taken into account. But, as we noted in Section 2, some researchers are very skeptical of the quality of peer review in research assessment exercises. Peer review as conducted in such exercises is not necessarily superior to a well-constructed citation analysis, which our artificial exercise here is certainly not. We believe that the findings in this paper greatly strengthen the case put by Stern (2014) for greater use of citation analysis in research assessment in economics. We predict that similar results would be obtained also for political science given the similarity between the results for that discipline and economics at the article level (Stern, 2014). 
1

2 Adams, J. (2005), 'Early citation counts correlate with accumulated impact', Scientometrics, 3 63(3), 567-81.

4 Anderson, D. L. and Tressler, J. (2014), 'The New Zealand performance based research fund 5 and its impact on publication activity in economics', Research Evaluation, 23(1), 1-11.

6 Bertocchi, G., Gambardella, A., Jappelli, T., Nappi, C. A. and Peracchi, F. (2015),

7 'Bibliometric evaluation vs. informed peer review: Evidence from Italy', Research Policy,

$8 \quad \mathbf{4 4}(2), 451-66$.

9 Bornmann, L. (2011), 'Scientific peer review', Annual Review of Information Science and 10 Technology, 45, 199-245.

Bornmann, L. (in press) 'How much does the expected number of citations for a publication change if it contains the address of a specific scientific institution? A new approach for the analysis of citation data on the institutional level based on regression models', Journal of the Association for Information Science and Technology.

Bornmann, L. and Leydesdorff, L. (2014), 'Scientometrics in a changing research landscape’, EMBO Reports, 15(12) 1228-32.

Clerides, S., Pashardes, P. and Polycarpou, A. (2011), 'Peer review vs metric-based assessment: testing for bias in the RAE ratings of UK economics departments', Economica, 78(311), 565-83.

Colman, A. M., Dhillon, D. and Coulthard, B. (1995), 'A bibliometric evaluation of the research performance of British university politics departments: Publications in leading journals', Scientometrics, 32(1), 49-66.

Department for Business, Innovation \& Skills and Johnson, J. (2015) 'Press release:

Government launches review to improve university research funding', URL: https://www.gov.uk/government/news/government-launches-review-to-improve-universityresearch-funding

Farla, K. and Simmonds, P. (2015), REF Accountability Review: Costs, Benefits and Burden. Report by Technopolis to the four UK higher education funding bodies.

Gallo, S. A., Carpenter, A. S., Irwin, D., McPartland, C. D., Travis, J., Reynders, S., Thompson, L. A., and Glisson, S. R. (2014), 'The validation of peer review through research impact measures and the implications for funding strategies', PLoS ONE 9(9): e106474. 
1 HEFCE (2015), The Metric Tide: Correlation Analysis of REF2014 Scores and Metrics

2 (Supplementary Report II to the Independent Review of the Role of Metrics in Research

3 Assessment and Management). Higher Education Funding Council for England. DOI:

$4 \quad$ 10.13140/RG.2.1.3362.4162

5 Holgate, S. T. (2015), "A comment on "Scientometrics in a changing research landscape",

6 EMBO Reports, 16(3), 261.

7 Hudson, J. (2013), ‘Ranking journals’, Economic Journal, 123, F202-22.

8 Im, K. S., Pesaran, M. H., and Shin, Y. (2003), 'Testing for unit roots in heterogeneous

9 panels', Journal of Econometrics, 115, 53-74.

10 Johnston, J., Reeves, A., and Talbot, S. (2014), 'Has economics become an elite subject for 11 elite UK universities?' Oxford Review of Education, 40(5), 590-609.

12 Kenna, R. and Berche, B. (2011), 'Critical mass and the dependency of research quality on 13 group size', Scientometrics, 86(2), 527-540.

14 Key Perspectives Ltd (2009), A Comparative Review of Research Assessment Regimes in 15 Five Countries and the Role of Libraries in the Research Assessment Process: A Pilot Study. 16 OCLC Research.

17 Levitt, J. M. and Thelwall, M. (2011), 'A combined bibliometric indicator to predict article impact', Information Processing and Management, 47, 300-8.

Moed, H. (2010), 'Measuring contextual citation impact of scientific journals', Journal of Informetrics, 4(3), 265-77.

Mryglod, O., Kenna, R., Holovatch, Y., and Berche, B. (2013), 'Comparison of a citationbased indicator and peer review for absolute and specific measures of research-group excellence', Scientometrics, 97, 767-77.

Mryglod, O., Kenna, R., Holovatch, Y., and Berche, B. (2015), 'Predicting results of the Research Excellence Framework using departmental h-index', Scientometrics, 102(3), 216580 .

27 Neri, F. and Rodgers, J. (2015), 'The contribution of Australian academia to the world's best 28 economics research: 2001 to 2010', Economic Record, 91(292), 107-24.

29 Norris, M. and Oppenheim, C. (2003), 'Citation counts and the research assessment exercise 30 V: Archaeology and the 2001 RAE', Journal of Documentation, 59(6), 709-30. 
1 Oppenheim, C. (1996), 'Do citations count? Citation indexing and the research assessment

2 exercise', Serials, 9, 155-61.

3 Ostriker, J. P., Kuh, C. V., and Voytuk, J. A. (eds.) (2011) A Data-Based Assessment of

4 Research-Doctorate Programs in the United States. Committee to Assess Research-Doctorate

5 Programs; National Research Council.

6 Regibeau, P. and Rockett, K. E. (2014), 'A tale of two metrics: Research assessment vs.

7 recognized excellence', University of Essex, Department of Economics, Discussion Paper

8 Series 757.

9 Sayer, D. (2014), Rank Hypocrisies: The Insult of the REF. Sage.

10 Sgroi, D. and Oswald, A. J. (2013), 'How should peer-review panels behave?' Economic 11 Journal, 123, F255-78.

12 Stern, D. I. (2014), 'High-ranked social science journal articles can be identified from early

13 citation information', PLOS ONE, 9(11), art. e112520.

14 Süssmuth, B., Steininger, M., and Ghio, S. (2006), 'Towards a European economics of

15 economics: Monitoring a decade of top research and providing some explanation',

16 Scientometrics, 66(3), 579-612.

17 Waltman, L. and van Eck N. J. (2013), 'Source normalized indicators of citation impact: an 18 overview of different approaches and an empirical comparison,' Scientometrics, 96 3, 69919716.

20 Waltman, L., van Eck N. J., van Leeuwen, T. N., Visser, M. S., and van Raan, A .F. J. (2011), 21 'Towards a new crown indicator: An empirical analysis', Scientometrics, 87, 467-81.

22 Waltman, L., Calero-Medina, C., Kosten, J., Noyons, E.C.M., Tijssen, R. J. W., Van Eck, N. 23 J., Van Leeuwen, T. N., Van Raan, A. F. J., Visser, M. S., and Wouters, P. (2012), 'The 24 Leiden Ranking 2011/2012: Data collection, indicators, and interpretation', Journal of the 25 American Society for Information Science and Technology, 63, 2419-32.

26 Wang, D., Song, C. and Barabási, A.-L. (2013), 'Quantifying long-term scientific impact', 27 Science, 342, 127-32.

28 Wang, J. (2013), 'Citation time window choice for research impact evaluation', 29 Scientometrics, 94(3), 851-72.

30 Wilsdon, J., et al. (2015), The Metric Tide: Report of the Independent Review of the Role of 31 Metrics in Research Assessment and Management. Higher Education Funding Council for 32 England. DOI: 10.13140/RG.2.1.4929.1363 
1 Wooding S., van Leeuwen, T. N., Parks, S., Kapur, S., and Grant, J. (2015), 'UK doubles its

2 "world-leading" research in life sciences and medicine in six years: testing the claim?' PLoS 3 ONE 10(7): e0132990.

4 
1 Table 1. Rank Correlations of Universities and Articles based on Early and Cumulative

2 Citations

\begin{tabular}{|c|c|c|c|c|c|c|c|}
\hline & & \multicolumn{3}{|c|}{ Australia } & \multicolumn{3}{|c|}{ United Kingdom } \\
\hline & & 2003 & $2003-4$ & $2003-5$ & 2003 & $\begin{array}{l}2003- \\
4\end{array}$ & $2003-5$ \\
\hline \multirow{8}{*}{$\begin{array}{l}2003 \\
\text { Articles }\end{array}$} & Total citations & & & & & & \\
\hline & Article & 0.22 & 0.44 & 0.65 & 0.28 & 0.54 & 0.70 \\
\hline & University & 0.66 & 0.88 & 0.92 & 0.82 & 0.92 & 0.97 \\
\hline & $\begin{array}{l}\text { Submitted to RAE } 2008 \text { / } \\
\text { ERA } 2010\end{array}$ & 0.66 & 0.88 & 0.92 & 0.86 & 0.96 & 0.98 \\
\hline & $\begin{array}{l}\text { Number of Articles in Top } \\
10 \%\end{array}$ & & & & & & \\
\hline & University & 0.72 & 0.84 & 0.84 & 0.69 & 0.70 & 0.89 \\
\hline & $\begin{array}{l}\text { Submitted to RAE } 2008 \text { / } \\
\text { ERA } 2010\end{array}$ & 0.71 & 0.83 & 0.84 & 0.73 & 0.77 & 0.90 \\
\hline & & 2004 & $2004-5$ & $2004-6$ & 2004 & $\begin{array}{l}2004- \\
5\end{array}$ & $2004-6$ \\
\hline \multirow{8}{*}{$\begin{array}{l}2004 \\
\text { Articles }\end{array}$} & Total citations & & & & & & \\
\hline & Article & 0.16 & 0.42 & 0.63 & 0.28 & 0.58 & 0.74 \\
\hline & University & 0.65 & 0.82 & 0.95 & 0.79 & 0.95 & 0.98 \\
\hline & $\begin{array}{l}\text { Submitted to RAE } 2008 \text { / } \\
\text { ERA } 2010\end{array}$ & 0.65 & 0.82 & 0.95 & 0.80 & 0.94 & 0.97 \\
\hline & $\begin{array}{l}\text { Number of Articles in Top } \\
10 \%\end{array}$ & & & & & & \\
\hline & University & 0.64 & 0.54 & 0.66 & 0.81 & 0.76 & 0.82 \\
\hline & $\begin{array}{l}\text { Submitted to RAE } 2008 \text { / } \\
\text { ERA } 2010\end{array}$ & 0.64 & 0.54 & 0.66 & 0.85 & 0.87 & 0.81 \\
\hline & & $2003-4$ & $2003-5$ & $2003-6$ & $2003-4$ & $\begin{array}{l}2003- \\
5\end{array}$ & $2003-6$ \\
\hline \multirow{6}{*}{$\begin{array}{l}2003 \\
\text { and } \\
2004 \\
\text { Articles }\end{array}$} & Total citations & & & & & & \\
\hline & University & 0.82 & 0.93 & 0.97 & 0.91 & 0.97 & 0.98 \\
\hline & $\begin{array}{l}\text { Submitted to RAE } 2008 \text { / } \\
\text { ERA } 2010\end{array}$ & 0.82 & 0.93 & 0.97 & 0.96 & 0.98 & 0.98 \\
\hline & $\begin{array}{l}\text { Number of Articles in Top } \\
10 \%\end{array}$ & & & & & & \\
\hline & University & 0.83 & 0.91 & 0.92 & 0.84 & 0.88 & 0.90 \\
\hline & $\begin{array}{l}\text { Submitted to RAE } 2008 / \\
\text { ERA } 2010\end{array}$ & 0.85 & 0.91 & 0.92 & 0.90 & 0.90 & 0.96 \\
\hline
\end{tabular}

Notes: Rank correlations between university and article rankings based on early citations and university and article rankings based on cumulative citations as well as rank correlations between university rankings based on

5 the number of articles in the top $10 \%$ of articles by early citations and by cumulative citations are shown.

6 Cumulative citations are based on citations from 2003 to 2014 ("2003 Articles" and "2003 and 2004 Articles")

7 and on 2004 to 2014 ("2004 Articles"). The rows labeled "Article" present the rank correlations at the article

8 level. The rows labeled "University" give the rank correlations when articles are aggregated by university. The

9 table also shows the rank correlations excluding universities that did not make submissions in economics to

10 ERA 2010 (Australia) or RAE 2008 (UK). Rank correlations at the article level for the combined articles of

112003 and 2004 are not presented, as this would require a comparable citation window for articles published in

122003 and 2004. However, a citation window of, for example, two years uses citations received in 2004 to 2005

13 for articles published in 2004 but it only uses citations received in 2003 to 2004 for articles published in 2003.

14 As such a ranking could be only made in 2005 , information on the citations received in 2005 for articles

15 published in 2003 would be ignored. 
1 Table 2. Rank Correlations of Universities Based on Research Assessment Scores and 2 Early and Cumulative Citations

\begin{tabular}{|c|c|c|c|c|c|}
\hline & & 2003 & $2003-4$ & $2003-5$ & 2003-14 \\
\hline \multirow[t]{13}{*}{2003 Articles } & Total Citations & & & & \\
\hline & ERA 2010 & 0.65 & 0.68 & 0.78 & 0.80 \\
\hline & RAE 2008 (Strength) & 0.65 & 0.70 & 0.69 & 0.63 \\
\hline & RAE 2008 (Quality) & 0.62 & 0.68 & 0.67 & 0.65 \\
\hline & RAE 2008 Funding (Strength) & 0.67 & 0.73 & 0.72 & 0.67 \\
\hline & RAE 2008 Funding (Quality) & 0.63 & 0.71 & 0.70 & 0.68 \\
\hline & Number of Articles in Top $10 \%$ & & & & \\
\hline & ERA 2010 & 0.73 & 0.74 & 0.80 & 0.73 \\
\hline & RAE 2008 (Strength) & 0.63 & 0.63 & 0.52 & 0.48 \\
\hline & RAE 2008 (Quality) & 0.61 & 0.59 & 0.41 & 0.41 \\
\hline & RAE 2008 Funding (Strength) & 0.66 & 0.65 & 0.52 & 0.48 \\
\hline & RAE 2008 Funding (Quality) & 0.62 & 0.62 & 0.43 & 0.44 \\
\hline & & 2004 & $2004-5$ & $2004-6$ & $2004-14$ \\
\hline \multirow[t]{13}{*}{2004 Articles } & Total Citations & & & & \\
\hline & ERA 2010 & 0.66 & 0.63 & 0.70 & 0.73 \\
\hline & RAE 2008 (Strength) & 0.57 & 0.68 & 0.66 & 0.64 \\
\hline & RAE 2008 (Quality) & 0.52 & 0.61 & 0.58 & 0.61 \\
\hline & RAE 2008 Funding (Strength) & 0.59 & 0.69 & 0.67 & 0.65 \\
\hline & RAE 2008 Funding (Quality) & 0.53 & 0.62 & 0.60 & 0.61 \\
\hline & Number of Articles in Top $10 \%$ & & & & \\
\hline & ERA 2010 & 0.72 & 0.63 & 0.64 & 0.56 \\
\hline & RAE 2008 (Strength) & 0.56 & 0.56 & 0.58 & 0.48 \\
\hline & RAE 2008 (Quality) & 0.51 & 0.51 & 0.55 & 0.42 \\
\hline & RAE 2008 Funding (Strength) & 0.59 & 0.59 & 0.61 & 0.49 \\
\hline & RAE 2008 Funding (Quality) & 0.54 & 0.54 & 0.57 & 0.44 \\
\hline & & $2003-4$ & $2003-5$ & $2003-6$ & $2003-14$ \\
\hline 2003 and 2004 & Total Citations & & & & \\
\hline \multirow[t]{11}{*}{ Articles } & ERA 2010 & 0.69 & 0.76 & 0.77 & 0.81 \\
\hline & RAE 2008 (Strength) & 0.69 & 0.69 & 0.67 & 0.67 \\
\hline & RAE 2008 (Quality) & 0.68 & 0.67 & 0.64 & 0.69 \\
\hline & RAE 2008 Funding (Strength) & 0.73 & 0.72 & 0.69 & 0.70 \\
\hline & RAE 2008 Funding (Quality) & 0.71 & 0.69 & 0.66 & 0.71 \\
\hline & Number of Articles in Top $10 \%$ & & & & \\
\hline & ERA 2010 & 0.76 & 0.82 & 0.83 & 0.78 \\
\hline & RAE 2008 (Strength) & 0.64 & 0.61 & 0.56 & 0.53 \\
\hline & RAE 2008 (Quality) & 0.64 & 0.58 & 0.50 & 0.49 \\
\hline & RAE 2008 Funding (Strength) & 0.66 & 0.64 & 0.57 & 0.54 \\
\hline & RAE 2008 Funding (Quality) & 0.66 & 0.61 & 0.52 & 0.50 \\
\hline
\end{tabular}

3 Notes: Rank correlations between university rankings based on the score received in ERA 2010 or RAE 2008 4 and both university rankings based on early and cumulative citations as well as university rankings based on the 5 number of articles in the top $10 \%$ of articles by early and cumulative citations are shown. RAE 2008 (Quality) 6 denotes the quality measure of RAE 2008 and RAE 2008 (Strength) denotes the strength measure of RAE 2008.

7 RAE 2008 Funding denotes the weighting by 9,3,1,0 instead of 4,3,2,1 (please see Methods section). For

8 example, 0.65 in the first row is the rank correlation between the university ranking based on ERA 2010 and the

9 university ranking based on citations received in 2003 for articles published in 2003 . At the end of this row, 0.80 
1 denotes the rank correlation between the university ranking based on ERA2010 and the university ranking based 2 on cumulative citations (2003-14) for articles published in 2003. 
1 Table 3: Rankings of Universities evaluated by the Research Assessment Exercise 2008 2 (Strength) and Total Citations

\begin{tabular}{|c|c|c|c|c|c|c|c|}
\hline \multirow[b]{2}{*}{ University } & \multicolumn{2}{|c|}{ RAE } & \multicolumn{3}{|c|}{2003 and 2004 Articles } & \multirow{2}{*}{$\begin{array}{c}2003 \\
\text { Articles } \\
2003-14\end{array}$} & \multirow{2}{*}{$\begin{array}{c}2004 \\
\text { Articles } \\
2003-14\end{array}$} \\
\hline & Funding & Original & 2003-4 & $2003-5$ & 2003-14 & & \\
\hline Univ Oxford & 1 & 1 & 2 & 2 & 2 & 4 & 2 \\
\hline LSE & 2 & 4 & 1 & 1 & 1 & 1 & 1 \\
\hline Univ Warwick & 3 & 2 & 6 & 4 & 4 & 7 & 3 \\
\hline Univ Nottingham & 4 & 3 & 7 & 5 & 7 & 8 & 6 \\
\hline UCL & 5 & 7 & 5 & 7 & 5 & 5 & 4 \\
\hline Univ Essex & 6 & 6 & 15 & 15 & 16 & 20 & 14 \\
\hline Univ Cambridge & 7 & 5 & 3 & 3 & 3 & 2 & 5 \\
\hline Univ Manchester & 8 & 9 & 10 & 9 & 10 & 9 & 9 \\
\hline Univ York & 9 & 8 & 8 & 8 & 8 & 10 & 7 \\
\hline Univ Southampton & 10 & 10 & 16 & 15 & 20 & 17 & 23 \\
\hline Queen Mary Univ & 11 & 13 & 11 & 18 & 14 & 12 & 25 \\
\hline Univ Leicester & 12 & 11 & 17 & 14 & 19 & 15 & 18 \\
\hline Birkbeck Coll & 13 & 14 & 20 & 22 & 23 & 21 & 29 \\
\hline Univ Bristol & 14 & 18 & 19 & 19 & 15 & 19 & 15 \\
\hline Royal Holloway Univ & 15 & 15 & 23 & 24 & 24 & 26 & 21 \\
\hline Univ Glasgow & 16 & 17 & 21 & 20 & 21 & 18 & 27 \\
\hline Univ St Andrews & 17 & 12 & 31 & 32 & 31 & 32 & 26 \\
\hline Univ Edinburgh & 18 & 20 & 4 & 6 & 6 & 3 & 16 \\
\hline Brunel Univ & 19 & 16 & 25 & 23 & 22 & 23 & 19 \\
\hline Univ Birmingham & 20 & 19 & 13 & 12 & 13 & 14 & 11 \\
\hline Swansea Univ & 21 & 22 & 31 & 30 & 27 & 29 & 22 \\
\hline Univ Exeter & 22 & 26 & 27 & 29 & 28 & 30 & 24 \\
\hline Univ Aberdeen & 23 & 25 & 17 & 17 & 18 & 16 & 17 \\
\hline Univ Sheffield & 24 & 23 & 9 & 11 & 11 & 13 & 8 \\
\hline Univ Surrey & 25 & 24 & 29 & 30 & 30 & 24 & 32 \\
\hline Univ Loughborough & 26 & 21 & 23 & 25 & 29 & 28 & 30 \\
\hline Univ Kent & 27 & 27 & 28 & 26 & 25 & 31 & 20 \\
\hline Univ E Anglia & 28 & 29 & 11 & 10 & 9 & 6 & 12 \\
\hline City Univ London & 29 & 28 & 22 & 21 & 17 & 21 & 13 \\
\hline Univ Dundee & 30 & 30 & 25 & 26 & 32 & 27 & 33 \\
\hline Univ Sussex & 31 & 31 & 14 & 13 & 12 & 11 & 10 \\
\hline Univ Stirling & 32 & 32 & 33 & 26 & 25 & 25 & 28 \\
\hline London Metropolitan & & & & & & & \\
\hline Univ & 33 & 33 & 33 & 35 & 34 & 33 & 35 \\
\hline Kingston Univ & 34 & 35 & 30 & 33 & 35 & 35 & 34 \\
\hline
\end{tabular}

Manchester

Metropolitan Univ

35

34

$33 \quad 33 \quad 33$

34

31

3 Notes: RAE Funding and Original denote the strength rankings of the Research Assessment Exercise in 2008

4 based on the weighting 9,3,2,0 and 4,3,2,1, respectively. The remaining rankings are based on cumulative

5 citations for articles published in 2003, 2004, as well as 2003 and 2004. 2003-2004, 2003-2005, and 2003-2014

6 denote the window over which citations are cumulated. 


\section{Table 4: Rankings of Universities evaluated by the Excellence in Research for Australia} 22010 and Total Citations

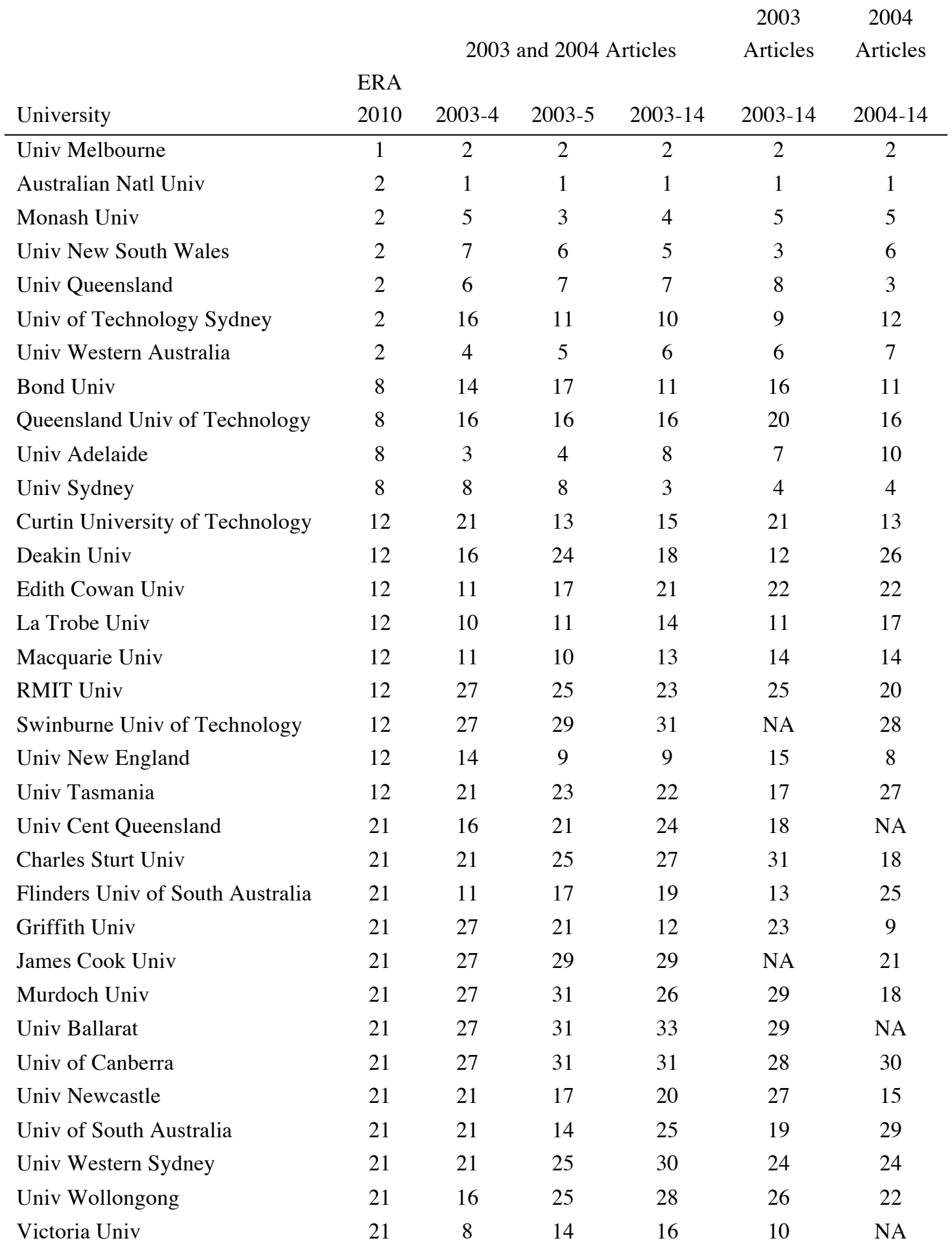

3 Notes: ERA 2010 denotes the ranking of the Excellence in Research for Australia in 2010 and the remaining 4 rankings are based on cumulative citations for articles published in 2003, 2004, as well as 2003 and 2004. 20035 2004, 2003-2005, and 2003-2014 denote the window over which citations are cumulated. NA denotes that no 6 economics article was published by this university in the respective year that is listed in the Web of Science. 
2 Table 5: Characteristics of Universities with Divergent Ranks in the United Kingdom

3

\begin{tabular}{|c|c|c|c|c|c|c|}
\hline & $\begin{array}{l}\text { RAE } 2008 \\
\text { FTE }\end{array}$ & $\begin{array}{l}\text { Number } \\
\text { of } \\
\text { Articles }\end{array}$ & Ratio & $\begin{array}{l}\text { Citations } \\
\text { of most } \\
\text { cited } \\
\text { paper }\end{array}$ & $\begin{array}{l}\text { Field of most } \\
\text { cited paper }\end{array}$ & Most Common Journal \\
\hline Univ & $\mathrm{St}$ & & & & & \\
\hline Andrews & 27.15 & 27 & 0.99 & 52 & Finance & $\begin{array}{l}\text { Applied Econ, Econ Letts } \\
\text { Econ J, J Econ Theory, }\end{array}$ \\
\hline Univ Essex & 34.31 & 51 & 1.49 & 57 & Labor & Manchester School \\
\hline Univ & & & & & & \\
\hline Edinburgh & 18 & 31 & 1.72 & 1509 & Econometrics & Economy and Society \\
\hline Univ Sheffield & 15 & 48 & 3.20 & 424 & Health & Health Economics \\
\hline Univ E Anglia & 13.5 & 49 & 3.63 & 286 & Environmental & $\begin{array}{l}\text { World Development } \\
\text { Industrial and Corporate Change, }\end{array}$ \\
\hline Univ Sussex & 10 & 46 & 4.60 & 158 & Health & World Economy \\
\hline
\end{tabular}

4 Notes: The table uses our data on 2003 and 2004 journal articles and the number of full-time equivalents that

5 submitted to the RAE 2008 (RAE 2008 FTE). Ratio denotes the number of articles published by one FTE in

62003 and 2004.

7 